\title{
STATISTICAL RESEARCH INTO LOW-POWER SOLAR FLARES. MAIN PHASE DURATION
}

\author{
A.V. Borovik \\ Institute of Solar-Terrestrial Physics SB RAS, \\ Irkutsk, Russia, aborovik@iszf.irk.ru
}

\author{
A.A. Zhdanov \\ Institute of Solar-Terrestrial Physics SB RAS, \\ Irkutsk,Russia,kick.out@mail.ru
}

\begin{abstract}
This paper is a sequel to earlier papers on time parameters of solar flares in the $\mathrm{H} \alpha$ line. Using data from the International Flare Patrol, an electronic database of solar flares for the period 1972-2010 has been created. The statistical analysis of the duration of the main phase has shown that it increases with increasing flare class and brightness. It has been found that the duration of the main phase depends on the type and features of development of solar flares. Flares with one brilliant point have the shortest main phase; flares with several intensity maxima and two-ribbon flares, the longest one. We have identified more than 3000 cases
\end{abstract}

with an ultra-long duration of the main phase (more than 60 minutes). For $90 \%$ of such flares the duration of the main phase is 2-3 hrs, but sometimes it reaches 12 hrs.

Keywords: solar activity, solar flares.

\section{INTRODUCTION}

As is known, solar flares have two phases of development: initial (flash) phase and main phase. During the flash phase, the flare intensity increases to maximum values. In the main phase, it slowly decreases and in about an hour reaches the brightness level of flocculi. In some cases, the intensity decrease can last for a day [Smith, Smith, 1966; Svestka, 1976; Altyntsev et al., 1982; Priest, 1985].

Detailed statistical studies of the flash phase have been carried out in [Borovik, Zhdanov, 2018]. This work examines flare decay time - the duration of the main phase of flares. We focus on low-power flares with an area of less than 2 square degrees, which comprise most solar flares (more than $90 \%$ ). In recent decades, specific studies have been carried out in this area of research [Temmer et al., 2001; Giersch, 2013; Potzi et al., 2014]. The results of earlier studies have been obtained from relatively small samples of data according to the first international classification of solar flares of 1956.

\section{DATABASE AND ITS ANALYSIS}

An electronic base of solar flares has been formed from catalogs of the Solar Geophysical Data (SGD) and Quarterly Bulletin on Solar Activity for the period from 1972 to 2010 in accordance with the modern optical classification of flares. It includes parameters of 123801 flares, 110778 of which are low-power, 11280 are class 1 flares, and 1743 are flares of class 2 and higher. In source directories, errors, misprints, and inaccuracies have been corrected. Duplication of the same events has been eliminated. The cases when stations did not report on the class of brightness or area, time of onset, maximum, and end of a flare, etc. are taken into account.

As repeatedly noted [Abramenko et al., 1960; Warwik, 1965; Smith, Smith, 1966; Kopetsky, Kopetsky,
1971; Ward et al., 1973; Rossada, 1977; Borovik, Zhdanov, 2017], the International Flare Patrol data suffer from a specific inhomogeneity. In particular, the time of flare maximum and end may differ in group reports of patrol stations. Therefore, we have estimated the variance of flare decay time for more than 20000 group reports from patrol stations. First, data obtained visually under poor observation conditions, summarized data, and reports with letter qualifiers (D, E, U and *) were excluded from the groups. In each group, we determined standard deviations of the flare decay time $(\sigma)$ and then averaged them over flare class and importance (Table 1, Figure 1):

$$
\sigma=\sqrt{\frac{1}{n-1} \sum_{i=1}^{n}\left(x_{i}-\bar{x}\right)^{2}} .
$$

The results we obtained suggest that as flare class and importance increase, $\bar{\sigma}$ gradually increases from 4.1 to $15.8 \mathrm{~min}$.

To reduce the variance, large samples of data or observations from a single station are generally used. We have implemented both the approaches.

\begin{tabular}{|l|r|r|}
\hline & \multicolumn{1}{|c|}{$N$} & $\bar{\sigma}$ \\
\hline SF & 8433 & 4.1 \\
\hline SN & 2991 & 5.4 \\
\hline SB & 699 & 5.3 \\
\hline $1 \mathrm{~F}$ & 161 & 6.0 \\
\hline $1 \mathrm{~N}$ & 469 & 8.2 \\
\hline $1 \mathrm{~B}$ & 395 & 8.6 \\
\hline$(2-4) \mathrm{F}$ & 13 & 9.5 \\
\hline$(2-4) \mathrm{N}$ & 65 & 9.3 \\
\hline$(2-4) \mathrm{B}$ & 161 & 15.8 \\
\hline S & 16352 & 4.9 \\
\hline 1 & 1697 & 8.7 \\
\hline $2-4$ & 359 & 14.3 \\
\hline
\end{tabular}

Table 1 


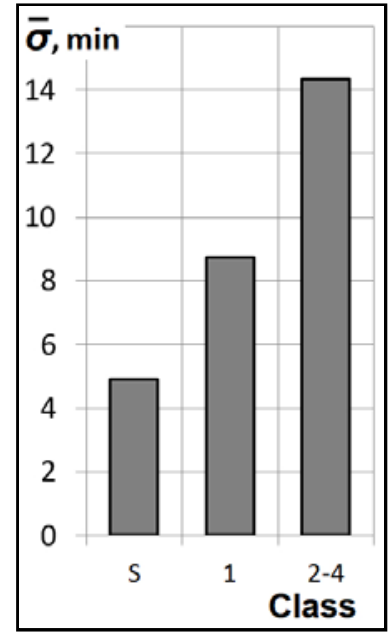

Figure 1. Change in $\bar{\sigma}$ depending on a flare class

\section{FLARE DECAY TIME ACCORDING TO DATA FROM ALL STATIONS}

In the statistical analysis, a number of restrictions were imposed on data as in [Borovik, Zhdanov, 2018].

- We ignored flares observed with poor image quality and flares with visually assessed parameters.

- Because of possible errors in identifying flare class and importance near the solar limb, class S and 1 flares that occurred further than $65^{\circ}$ from the central meridian were excluded from the database. For large flares (2-4), this restriction was not imposed.

- In group reports, we abandoned data generalized and marked with letter qualifiers of uncertainty. After applying all the above selection criteria, we chose observations from the station that had most reports in its database.

We have selected a total of 84628 flares. Their distribution over flare decay time (in percent of the total number of flares with increment of $1 \mathrm{~min}$ ) is depicted in Figure 2. The vertical dashed line indicates the position of the median. The tail of the distribution is scaled up (axis to the right).

This distribution is quite extended and asymmetric. The main phase of some flares lasted for more than $240 \mathrm{~min}$ (not shown in the Figure). To determine more precisely the main statistical parameters of the distribution, its range was limited to $191 \mathrm{~min}$ - the interval when the distribution continuity was violated. The unaccounted flares (69) are 0.08 $\%$. Then, we calculated the statistical parameters only within this interval.

Figures 3-5 show distributions of flare decay time for each class and importance of flares.

Statistical parameters of the distributions are given in Table 2. The Table lists the number of flares $(N)$, the mean flare decay time with the confidence interval $(\bar{t} \pm \alpha)$, modal (Mo) and median (Me) distribution parameters, time intervals for $90 \%$ of flares $(\Delta t)$.

The last four rows contain flare classes and summarized data $(\Sigma)$. Hereinafter, time parameters are given in minutes.

$$
\bar{t}-\Omega(P, n-1) \frac{\sigma}{\sqrt{n}} \leq \alpha \leq \bar{t}+\Omega(P, n-1) \frac{\sigma}{\sqrt{n}},
$$

Table 2

\begin{tabular}{|l|r|r|r|r|l|}
\hline & \multicolumn{1}{|c|}{$N$} & $\bar{t} \pm \alpha$ & Mo & Me & $\Delta t$ \\
\hline SF & 55069 & $12.8 \pm 0.1$ & 4 & 9 & $1-26$ \\
\hline SN & 18098 & $16.6 \pm 0.2$ & 8 & 12 & $1-34$ \\
\hline SB & 3817 & $20.0 \pm 0.6$ & 8 & 15 & $1-41$ \\
\hline $1 \mathrm{~F}$ & 1919 & $29.7 \pm 1.0$ & 12 & 24 & $1-59$ \\
\hline $1 \mathrm{~N}$ & 2843 & $33.2 \pm 1.0$ & 17 & 27 & $1-66$ \\
\hline $1 \mathrm{~B}$ & 1563 & $40.1 \pm 1.4$ & 21 & 33 & $1-76$ \\
\hline$(2-4) \mathrm{F}$ & 166 & $41.3 \pm 5.0$ & 17 & 33 & $1-84$ \\
\hline$(2-4) \mathrm{N}$ & 446 & $52.0 \pm 3.3$ & 16 & 44 & $1-105$ \\
\hline$(2-4) \mathrm{B}$ & 638 & $63.0 \pm 3.1$ & 35 & 55 & $1-121$ \\
\hline S & 76984 & $14.1 \pm 0.1$ & 4 & 10 & $1-29$ \\
\hline 1 & 6325 & $33.8 \pm 0.6$ & 12 & 27 & $1-66$ \\
\hline $2-4$ & 1250 & $56.3 \pm 2.1$ & 35 & 48 & $1-111$ \\
\hline$\Sigma$ & 84559 & $16.2 \pm 0.1$ & 4 & 11 & $1-34$ \\
\hline
\end{tabular}

where $\bar{t}$ is the mean flare decay time; $n$ is the number of data; $P$ is the confidence coefficient ( $95 \%) ; \Omega$ is Student's coefficient (1.96).

A change in the statistical parameters with an increase in flare class is illustrated in Figure 6.

The results obtained suggest that with an increase in the flare class and importance, the mean duration of the main phase increases from 12.8 to $63 \mathrm{~min}$, the mode shifts from 4 to $35 \mathrm{~min}$; the median, from 9 to $55 \mathrm{~min}$. Intervals for $90 \%$ of flares and standard deviations also increase.

The asymmetry and kurtosis of the distributions decrease.

Despite the fact that the confidence intervals for the flares of certain importance are fairly wide (for example, for (2-4)F flares), there is a clear relationship between the duration of intensity decrease and brightness characteristics of flares (Tables 3, 2).

\section{FLARE DECAY TIME FROM HOLL, LEAR, RAMY OBSERVATORY DATA}

Similar studies have been carried out using data from three observatories: HOLL - Holloman Solar Observatory (USA), LEAR - Learmonth Solar Observatory (Australia), and RAMY - Ramey Solar Observatory (Puerto Rico). The number of flares is given in Table 4, distribution parameters are shown in Figures 7, 8.

Table 3

\begin{tabular}{|c|c|c|c|c|c|}
\hline Brightness & $N$ & $\bar{t} \pm \alpha$ & Mo & Me & $\Delta t$ \\
\hline F & 69310 & $13.0 \pm 0.1$ & 4 & 9 & $1-27$ \\
\hline $\mathrm{N}$ & 25892 & $18.9 \pm 0.2$ & 8 & 13 & $1-39$ \\
\hline B & 7066 & $28.4 \pm 0.6$ & 8 & 20 & $1-62$ \\
\hline
\end{tabular}

As derived from HOLL, LEAR, and RAMY data, the mean decay times of low-power flares actually coincide (Figures 7, 8, $a$ ). For flares of higher classes, they diverge within the scattering interval $\bar{\sigma}$.

The results also confirm that the main phase duration increases with increasing class and importance of flares. 


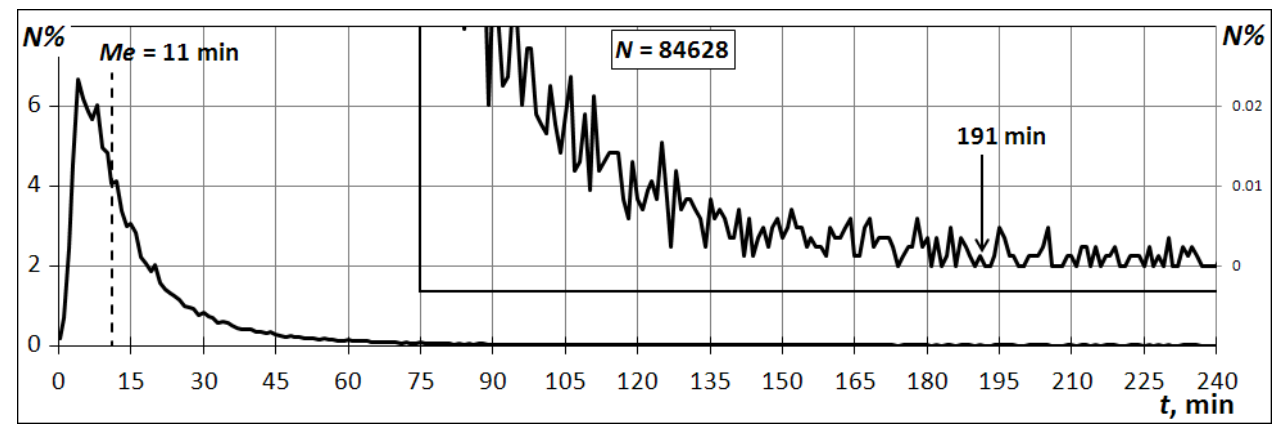

Figure 2. Distribution of flare decay time for all solar flares
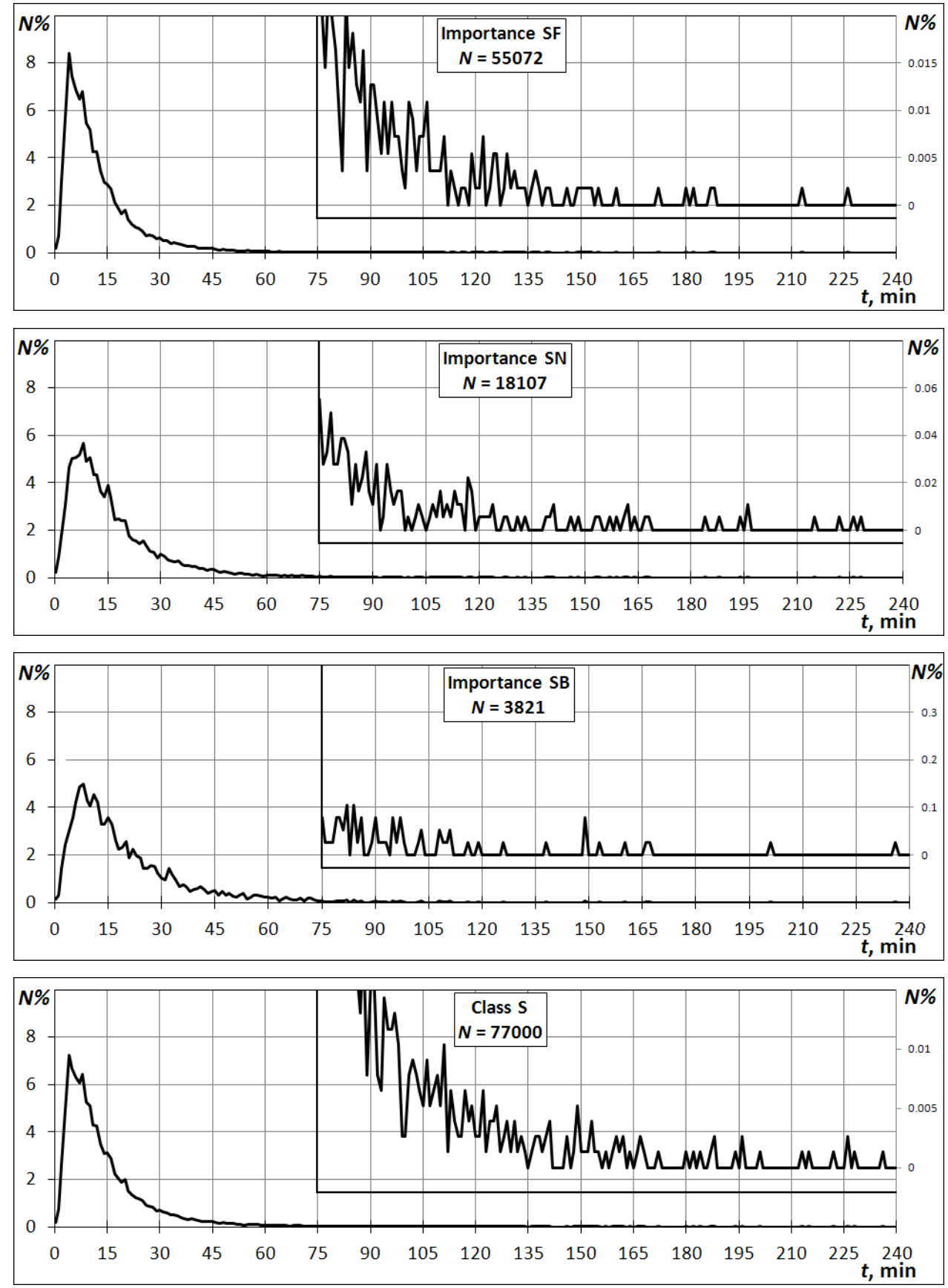

Figure 3. Distribution of flare decay time for class S flares 

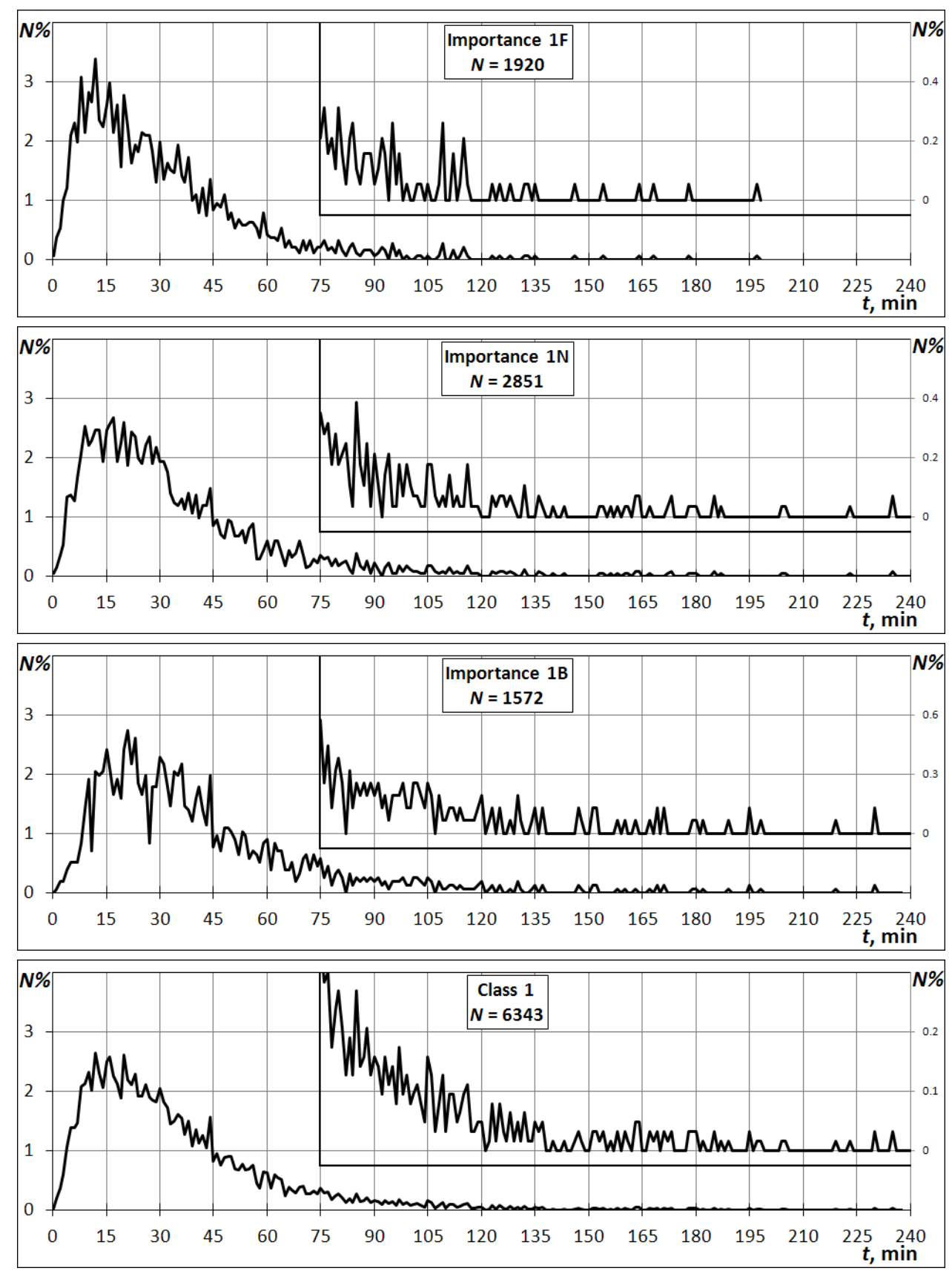

Figure 4. Distribution of flare decay time for class 1 flares

As a result of the extensive statistical study, we have first found the mean duration of the main phase of class S, 1, and 2-4 flares (Table 5, Column II). Column I presents the results [Temmer et al., 2001].

The smaller amount of data used in the statistical analysis than in [Temmer et al., 2001] is associated with a more rigorous approach to the selection of class $\mathrm{S}$ and 1 flares.

\section{FLARE DECAY TIME FOR SEPARATE TYPES OF FLARES}

Along with the well-defined tendency for an increase in the duration of the main phase with flare class, it is noteworthy that the distributions largely overlap (Figure $9, a)$. As a result, within the interval $\Delta t=1-111$ min characteristic of $90 \%$ of large flares there are $99.9 \%$ of lowpower flares and $98.1 \%$ of class 1 flares.

\begin{tabular}{|l|c|r|r|r|}
\hline \multirow{2}{*}{} & \multicolumn{4}{|c|}{ Number } \\
\cline { 2 - 5 } & all stations & \multicolumn{1}{|c|}{ HOLL } & \multicolumn{1}{c|}{ LEAR } & RAMY \\
\hline SF & 55069 & 14224 & 11815 & 8347 \\
\hline SN & 18098 & 2565 & 1638 & 1971 \\
\hline SB & 3817 & 974 & 342 & 838 \\
\hline 1F & 1919 & 326 & 453 & 175 \\
\hline 1N & 2843 & 420 & 446 & 199 \\
\hline 1B & 1563 & 368 & 249 & 199 \\
\hline$(2-4) \mathrm{F}$ & 166 & 27 & 35 & 9 \\
\hline$(2-4) \mathrm{N}$ & 446 & 59 & 78 & 29 \\
\hline$(2-4) \mathrm{B}$ & 638 & 156 & 150 & 79 \\
\hline S & 76984 & 17763 & 13795 & 11156 \\
\hline 1 & 6325 & 1114 & 1148 & 573 \\
\hline $2-4$ & 1250 & 242 & 263 & 117 \\
\hline$\Sigma$ & 84559 & 19119 & 15206 & 11846 \\
\hline
\end{tabular}



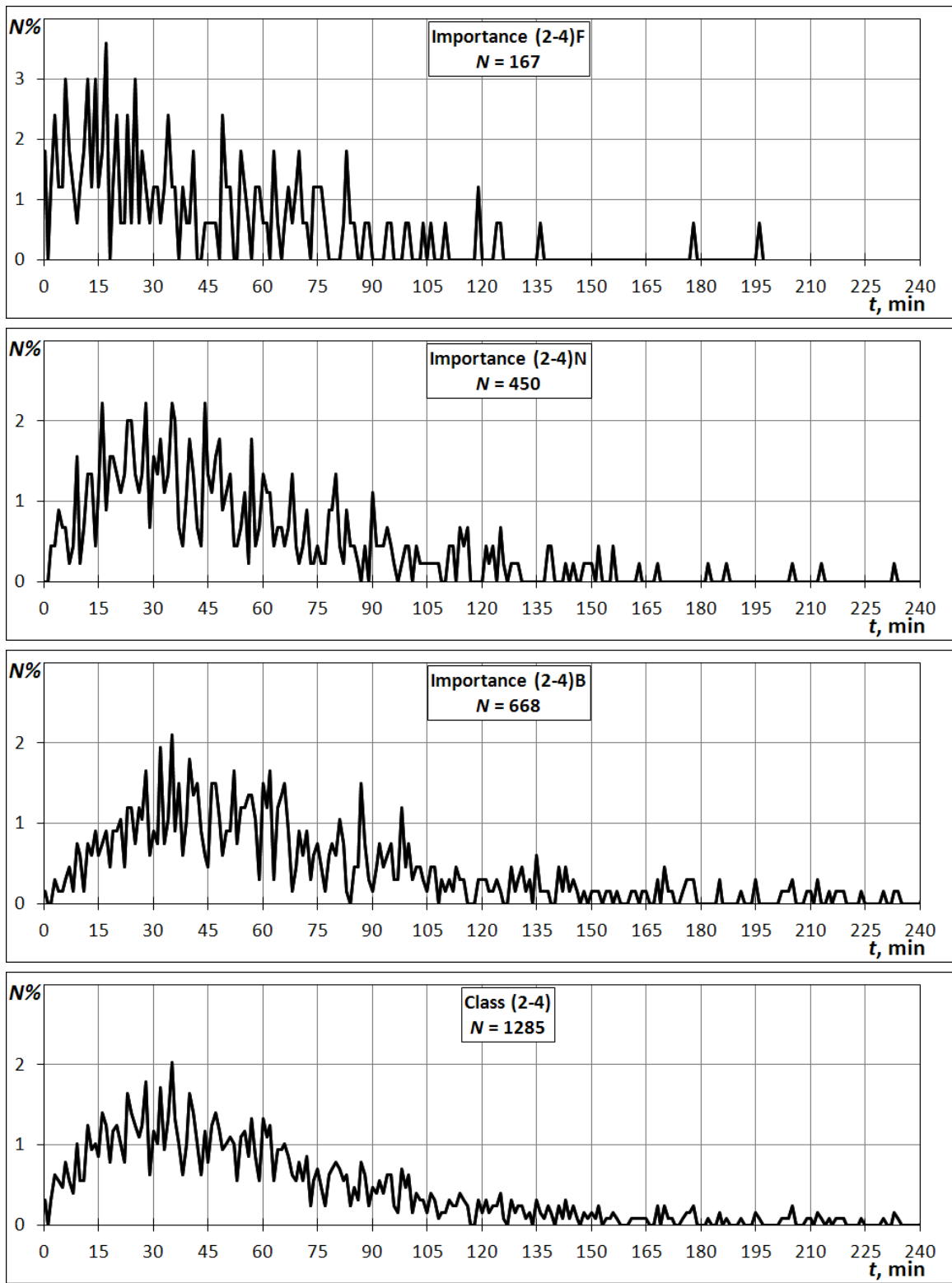

Figure 5. Distribution of flare decay time for class 2-4 flares

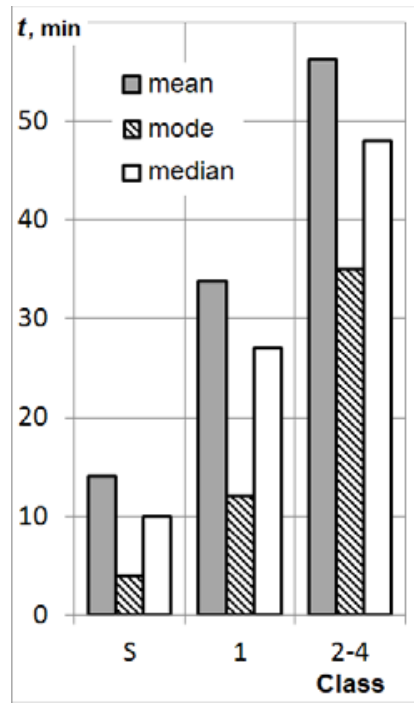

Figure 6. Change in statistical parameters of distributions with increasing flare class 


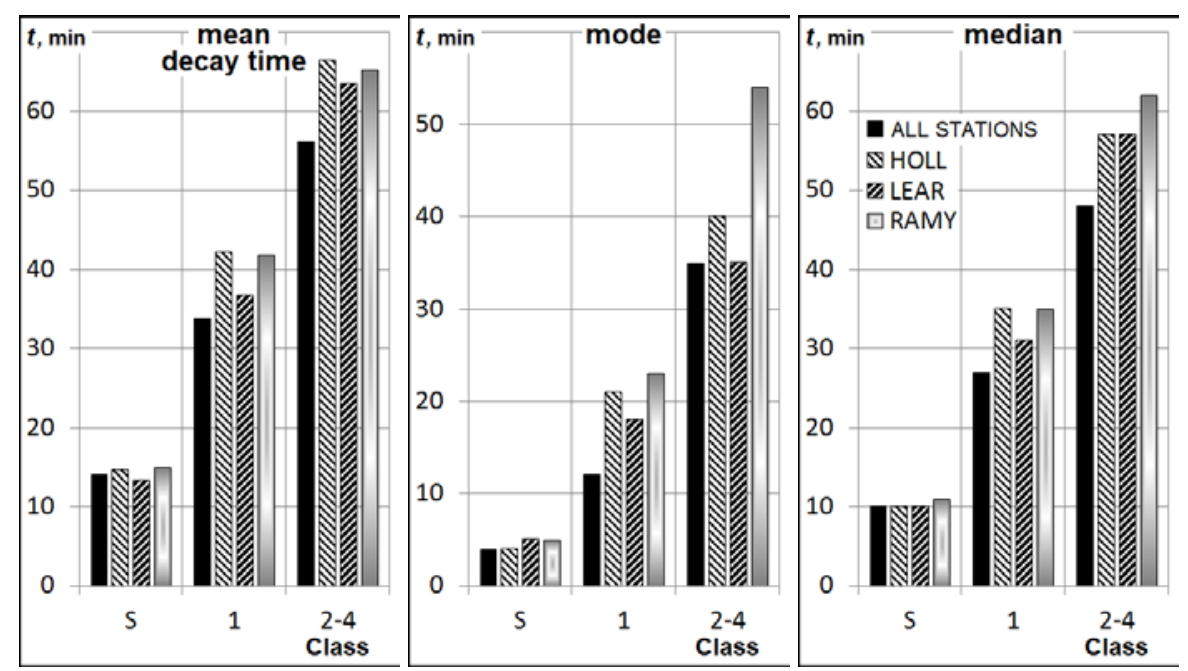

Figure 7. Change in statistical parameters of distributions with increasing flare class according to HOLL, LEAR, RAMY data
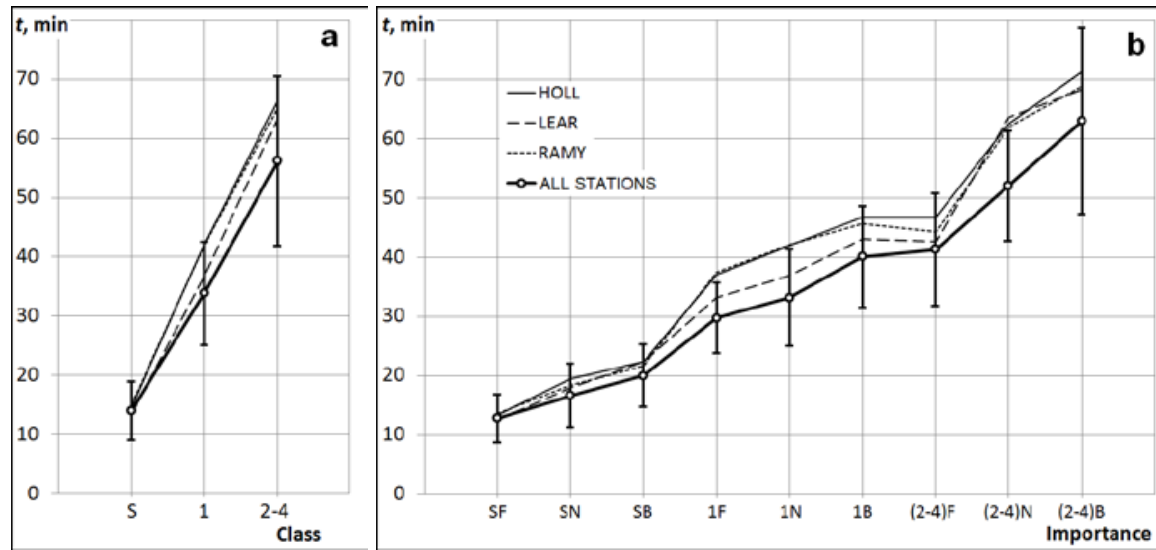

Figure 8. Change in the mean flare decay time with increasing class $(a)$ and importance of flares $(b)$ according to data from HOLL, LEAR, RAMY observatories and all stations. Vertical lines show scattering intervals $\bar{\sigma}$ (Figure 1 )

Table 5

\begin{tabular}{|l|r|r|r|r|r|r|c|c|}
\hline \multirow{2}{*}{ Class } & \multicolumn{2}{|c|}{ Number } & \multicolumn{2}{c|}{ Mean } & \multicolumn{2}{c|}{ Mode } & \multicolumn{2}{c|}{ Median } \\
\cline { 2 - 9 } & \multicolumn{1}{|c|}{ I } & \multicolumn{1}{|c|}{ II } & I & II & I & II & I & II \\
\hline S & 85649 & 76984 & - & 14.1 & - & 4 & 10 & 10 \\
\hline 1 & 9176 & 6325 & - & 33.8 & - & 12 & 22 & 27 \\
\hline $2-4$ & 1120 & 1285 & - & 61.0 & - & 35 & 45 & 49 \\
\hline$\Sigma$ & 95945 & 84559 & 15.5 & 16.2 & 8 & 4 & 11 & 11 \\
\hline
\end{tabular}

Figure 10 shows that there is no functional relationship between flare decay time and flare area. The scattering is quite significant, especially for low-power flares. The correlation coefficient does not exceed 0.4.

To find out the cause for the increase in $\bar{t}$ with increasing class, we have conducted a similar statistical analysis for individual types of flares.

On some of them, stations report in the form of remarks. The remark system, introduced by the International Flare Patrol [Solar-Geophysical Data, 1983], in general terms, characterizes a type of flare, its related events, generating area, size of active region, etc. Below is a list of the most important remarks:

- D - Brilliant point;

- E - Two or more brilliant points;

- $\mathrm{G}$ - No visible spots nearby;

- $\mathrm{H}$ - Flare accompanied by high-speed dark filament;
- $\mathrm{K}$ - Several intensity maxima;

- L - Existing filaments suddenly active;

- $\mathrm{M}$ - White-light flare;

- $\mathrm{R}$ - Asymmetry in H-alpha line suggests high speed mass ejection;

- S - Brightness followed filament disappearance in same position;

- U - Two bright branches, parallel or converging;

- V - Explosive phase: important expansion in about 1 min that often includes a significant intensity increase;

- W - Great area increase after time of maximum brightness;

- $\quad$ Z - Major sunspot umbra covered by flare.

The above features are observed in flares of all importance classes. 


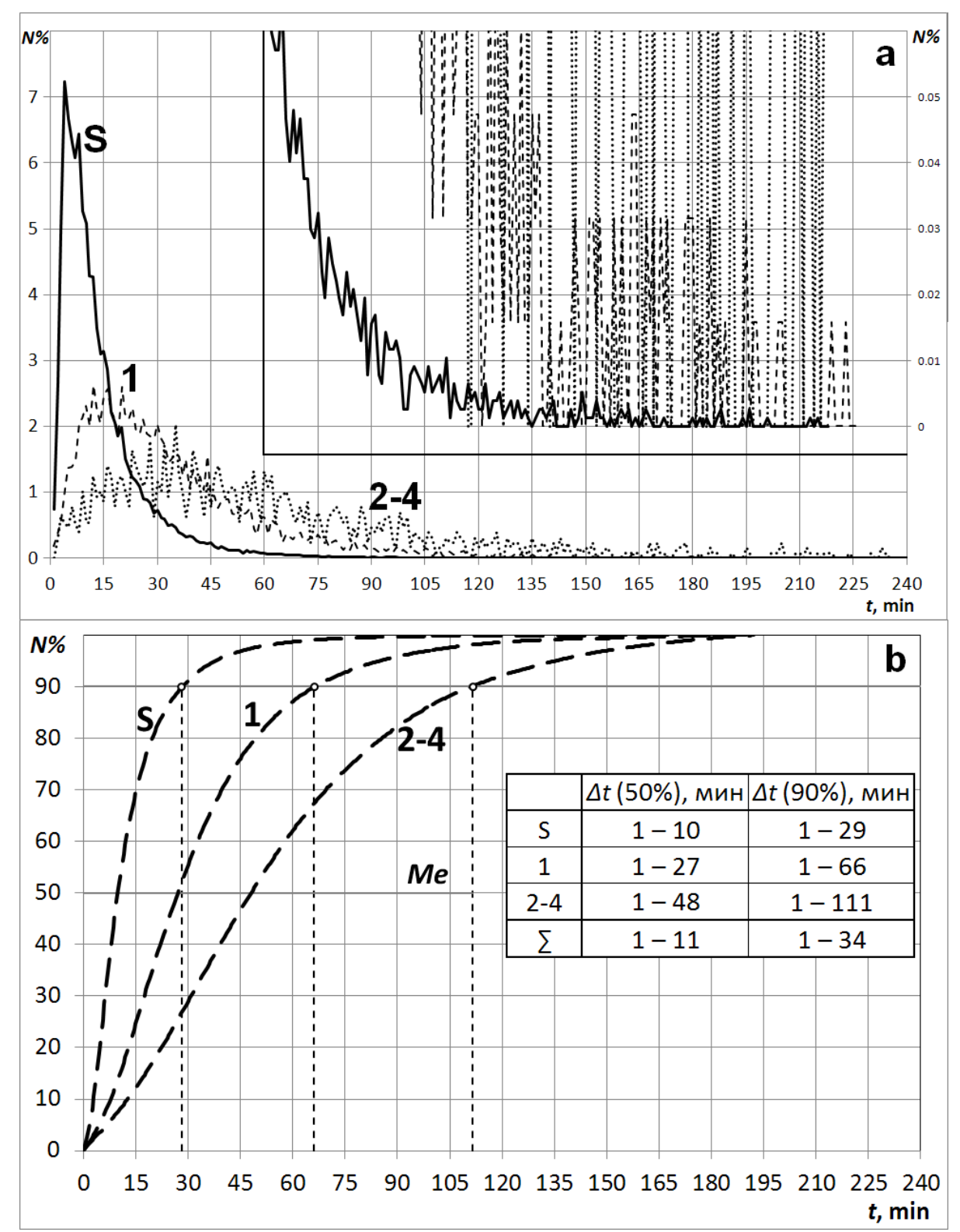

Figure 9. Panel $a$ shows distribution of flare decay time for class S, 1, 2-4 flares: the solid line indicates class S flares; the dashed line, class 1 flares; the dotted line, class 2-4 flares; tails of distributions are scaled up. Panel $b$ shows curves of cumulative frequencies; Table lists intervals for 50 and $90 \%$ of flares

Frequency of their occurrence is discussed in detail in [Borovik, Zhdanov, 2018]. Unfortunately, not all stations observe features of flare development; therefore, we have analyzed only those types of flares that have a sufficiently high statistical weight.

When calculating statistical parameters, we imposed the same restrictions on the data as on all flares. Because of the relatively small amount of data, the modal times of class 2-4 flares were estimated from smoothed distribution curves.

\section{$\mathrm{V}$ - and K-flares}

V-flares (explosive flares) are characterized by a rapid and significant increase in intensity and area.

K-flares feature several intensity maxima.

For the 1 and $\mathrm{S}$ classes, the mean decay time in $\mathrm{V}$ flare brightness is 2.2-1.4 times shorter than that in Kflares (Table 6, Figure 11). Median values in V-flares are 2.2-1.5 times shorter than those in K-flares. Intervals in V-flares are 2.2-1.1 shorter than those in Kflares for $90 \%$ of flares. There are no such differences for class 2-4 flares. One of the possible reasons is a small amount of data.

\section{U-flares (two-ribbon)}

U-flares are flares with parallel or converging bright ribbons.

The mean flare decay time for two-ribbon flares and other parameters of distributions far exceed those in all flares (Table 7, Figure 12).

\section{H-flares}

H-flares are accompanied by a high-speed dark filament.

The statistical parameters of $\mathrm{H}$-flares are closest to the parameters of all flares (Table 8, Figure 13). 


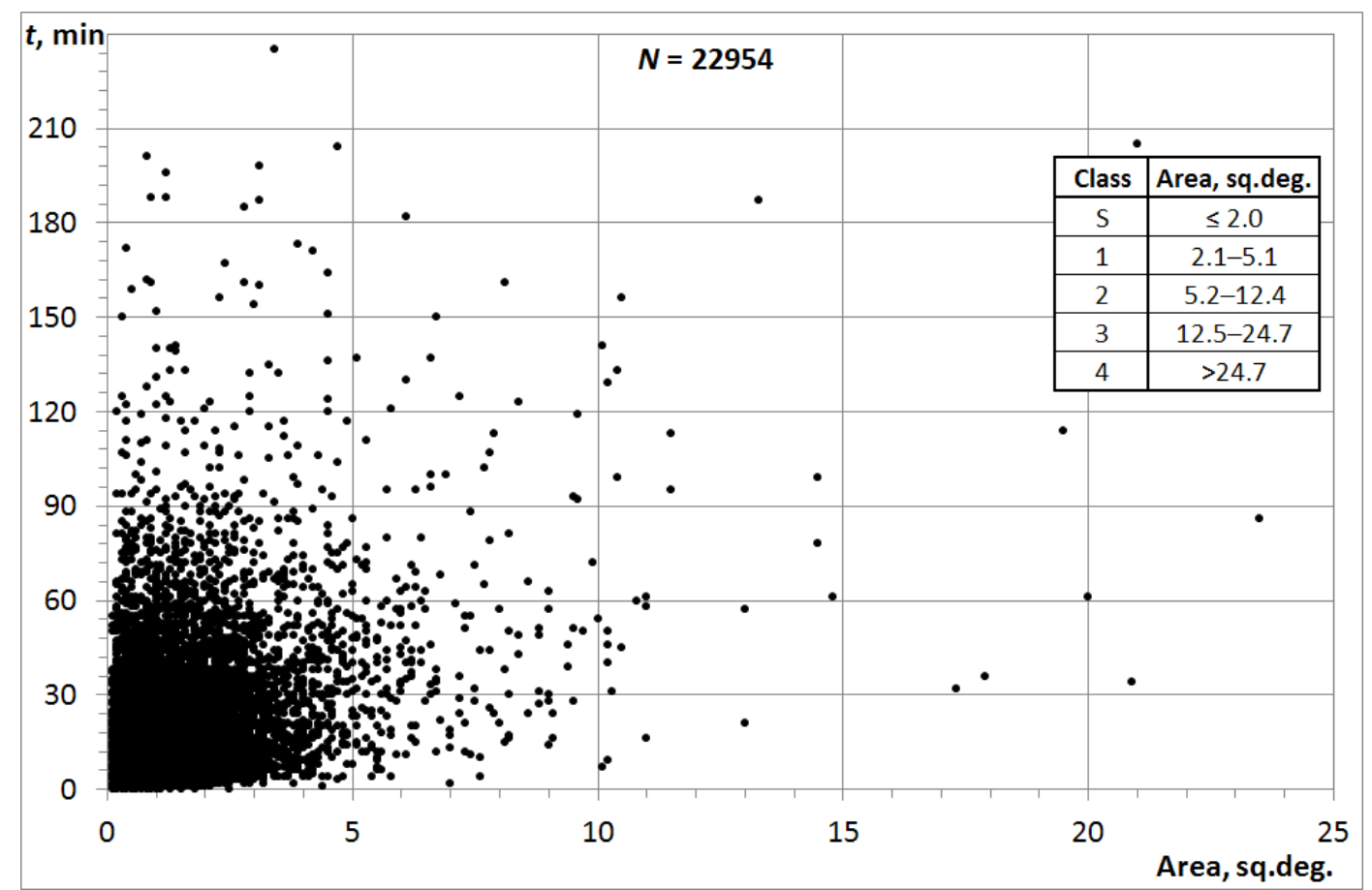

Figure 10. Duration of the main phase versus flare area. The Table shows the classification of solar flares in the Ha line

Table 6

\begin{tabular}{|c|c|c|c|c|c|c|c|c|c|}
\hline Class & \multicolumn{3}{|c|}{$\mathrm{S}$} & \multicolumn{2}{c|}{1} & \multicolumn{3}{c|}{$2-4$} \\
\hline $\begin{array}{c}\text { Type of } \\
\text { flare }\end{array}$ & $\begin{array}{c}\text { all } \\
\text { flares }\end{array}$ & $\mathrm{V}$ & $\mathrm{K}$ & $\begin{array}{c}\text { all } \\
\text { flares }\end{array}$ & $\mathrm{V}$ & $\mathrm{K}$ & $\begin{array}{c}\text { all } \\
\text { flares }\end{array}$ & $\mathrm{V}$ & $\mathrm{K}$ \\
\hline$N$ & 76984 & 2762 & 1021 & 6325 & 270 & 303 & 1250 & 47 & 94 \\
\hline $\bar{t} \pm \alpha$ & $14.1 \pm 0.1$ & $15.4 \pm 0.4$ & $33.5 \pm 1.6$ & $33.8 \pm 0.6$ & $36.6 \pm 3.3$ & $50.6 \pm 3.9$ & $56.2 \pm 2.1$ & $66.3 \pm 12.0$ & $67.6 \pm 7.5$ \\
\hline $\mathrm{Mo}$ & 4 & 8 & 18 & 12 & 20 & 36 & 35 & 44 & 48 \\
\hline $\mathrm{Me}$ & 10 & 12 & 26 & 27 & 28 & 42 & 48 & 54 & 61 \\
\hline$\Delta t$ & $1-29$ & $1-30$ & $1-65$ & $1-66$ & $1-72$ & $1-101$ & $1-111$ & $1-125$ & $1-126$ \\
\hline
\end{tabular}
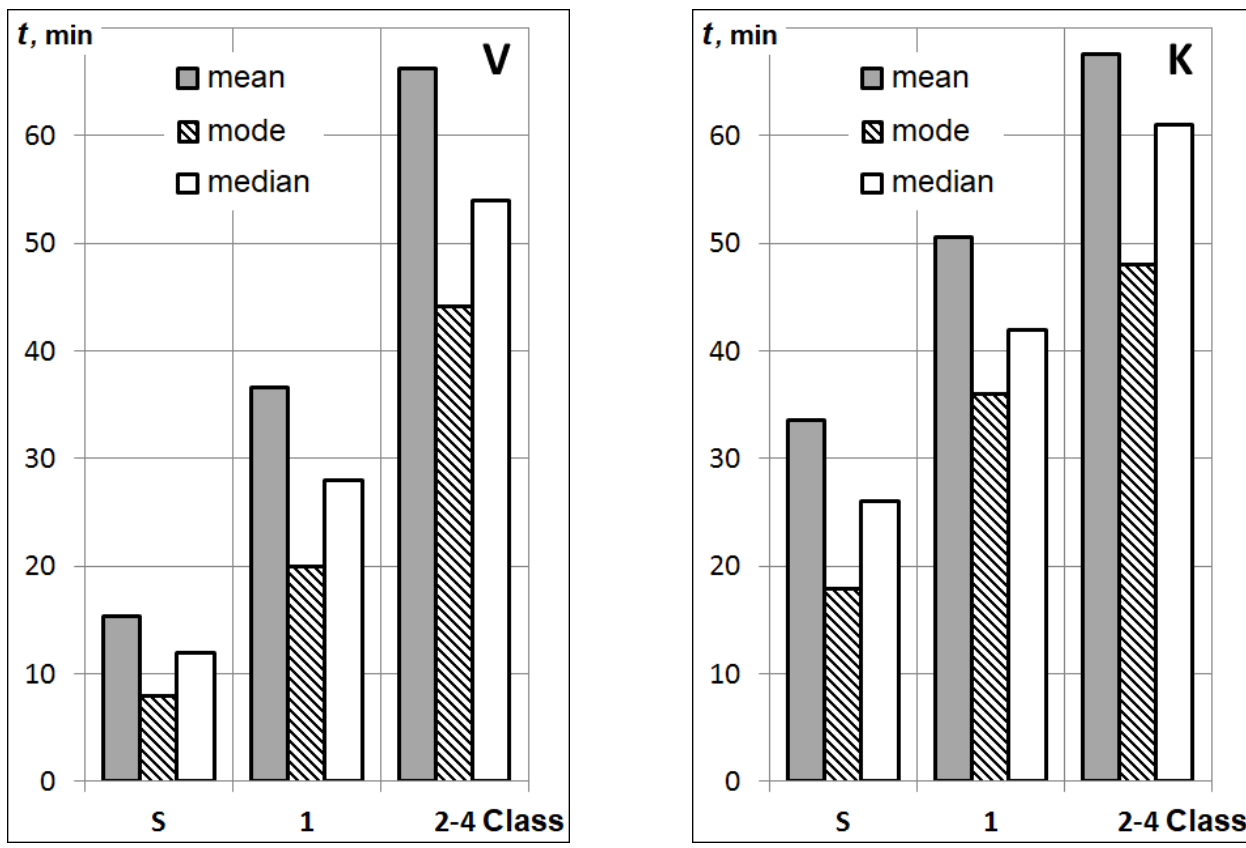

Figure 11. Statistical parameters of V-and K-flares 
Table 7

\begin{tabular}{|c|c|c|c|c|c|c|}
\hline Class & \multicolumn{2}{|c|}{$\mathrm{S}$} & \multicolumn{2}{c|}{1} & \multicolumn{2}{c|}{$2-4$} \\
\hline $\begin{array}{c}\text { type of } \\
\text { flare }\end{array}$ & $\begin{array}{c}\text { all } \\
\text { flares }\end{array}$ & $\mathrm{U}$ & $\begin{array}{c}\text { all } \\
\text { flares }\end{array}$ & $\mathrm{U}$ & $\begin{array}{c}\text { all } \\
\text { flares }\end{array}$ & $\mathrm{U}$ \\
\hline$N$ & 76984 & 569 & 6325 & 429 & 1250 & 215 \\
\hline $\bar{t} \pm \alpha$ & $14.1 \pm 0.1$ & $25.4 \pm 1.7$ & $33.8 \pm 0.6$ & $50.0 \pm 3.0$ & $56.2 \pm 2.1$ & $80.2 \pm 5.4$ \\
\hline $\mathrm{Mo}$ & 4 & 12 & 12 & 22 & 35 & 66 \\
\hline $\mathrm{Me}$ & 10 & 20 & 27 & 42 & 48 & 76 \\
\hline$\Delta t$ & $1-29$ & $1-53$ & $1-66$ & $1-93$ & $1-111$ & $1-38$ \\
\hline
\end{tabular}

Table 8

\begin{tabular}{|c|c|c|c|c|c|c|}
\hline Class & \multicolumn{2}{|c|}{$\mathrm{S}$} & \multicolumn{2}{c|}{1} & \multicolumn{2}{c|}{$2-4$} \\
\hline $\begin{array}{c}\text { type of } \\
\text { flare }\end{array}$ & $\begin{array}{c}\text { all } \\
\text { flares }\end{array}$ & $\mathrm{H}$ & $\begin{array}{c}\text { all } \\
\text { flares }\end{array}$ & $\mathrm{H}$ & $\begin{array}{c}\text { all } \\
\text { flares }\end{array}$ & $\mathrm{H}$ \\
\hline$N$ & 76984 & 2356 & 6325 & 429 & 1250 & 215 \\
\hline $\bar{t} \pm \alpha$ & $14.1 \pm 0.1$ & $14.3 \pm 0.5$ & $33.8 \pm 0.6$ & $29.5 \pm 2.0$ & $56.2 \pm 2.1$ & $49.8 \pm 5.5$ \\
\hline $\mathrm{Mo}$ & 4 & 4 & 12 & 13 & 35 & 37 \\
\hline $\mathrm{Me}$ & 10 & 10 & 27 & 24 & 48 & 46 \\
\hline$\Delta t$ & $1-29$ & $1-29$ & $1-66$ & $1-59$ & $1-111$ & $1-89$ \\
\hline
\end{tabular}

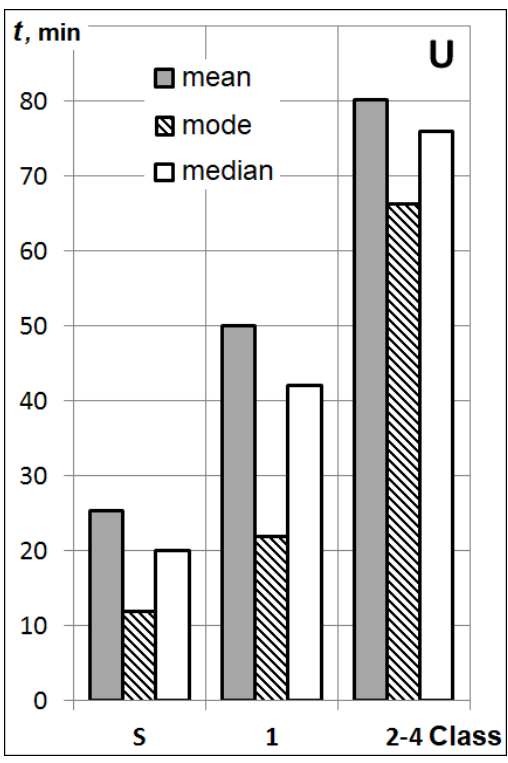

Figure 12. Statistical parameters of U-flares

\section{G-flares}

G-flares, or spotless flares, are rather rare events. According to various sources, their percent of the total number of flares is from 2 to 7 \% [Dodson, Hedeman, 1970; Chistyakov, 1988; Barlas, Altas, 1992, 1994; Yatini, 2001; Luo, 1985]. The majority of the flares are low-power. Spotless flares have been studied in detail in
[Borovik, Myachin, 2002, 2010; Borovik et al., 2016].

The statistical weight of data on G-flares is relatively low, especially for large flares. For spotless lowpower flares, the parameters are somewhat higher than those for all flares (Table 9, Figure 14).

Figure 13. Statistical parameters of H-flares

\section{D- and E-flares}

D-flares have one brilliant point; E-flares, two or more points. The statistical parameters of D- and Eflares are given in Table 10 and Figure 15.

Compared to E-flares, D-flares have a shorter mean flare decay time, shorter intervals, and lower median distributions for $90 \%$ of flares.

\begin{tabular}{|c|c|c|c|c|c|c|}
\hline Class & \multicolumn{2}{|c|}{$\mathrm{S}$} & \multicolumn{2}{c|}{1} & \multicolumn{2}{c|}{$2-4$} \\
\hline $\begin{array}{c}\text { type of } \\
\text { flare }\end{array}$ & $\begin{array}{c}\text { all } \\
\text { flares }\end{array}$ & $\mathrm{G}$ & $\begin{array}{c}\text { all } \\
\text { flares }\end{array}$ & $\mathrm{G}$ & $\begin{array}{c}\text { all } \\
\text { flares }\end{array}$ & $\mathrm{G}$ \\
\hline$N$ & 76984 & 484 & 6325 & 68 & 1250 & 215 \\
\hline $\bar{t} \pm \alpha$ & $14.1 \pm 0.1$ & $15.9 \pm 1.2$ & $33.8 \pm 0.6$ & $28.6 \pm 6.9$ & $56.2 \pm 2.1$ & $56.5 \pm 27.1$ \\
\hline $\mathrm{Mo}$ & 4 & 8 & 12 & 13 & 35 & 54 \\
\hline $\mathrm{Me}$ & 10 & 12 & 27 & 19 & 48 & 54 \\
\hline$\Delta t$ & $1-29$ & $1-31$ & $1-66$ & $1-69$ & $1-111$ & $1-116$ \\
\hline
\end{tabular}

Table 9 
Table 10

\begin{tabular}{|c|c|c|c|c|c|c|c|c|c|}
\hline Class & \multicolumn{3}{|c|}{$\mathrm{S}$} & \multicolumn{3}{c|}{1} & \multicolumn{3}{c|}{$2-4$} \\
\hline $\begin{array}{c}\text { type of } \\
\text { flare }\end{array}$ & $\begin{array}{c}\text { all } \\
\text { flares }\end{array}$ & $\mathrm{D}$ & $\mathrm{E}$ & $\begin{array}{c}\text { all } \\
\text { flares }\end{array}$ & $\mathrm{D}$ & $\mathrm{E}$ & $\begin{array}{c}\text { all } \\
\text { flares }\end{array}$ & $\mathrm{D}$ & $\mathrm{E}$ \\
\hline$N$ & 76984 & 3291 & 6856 & 6325 & 218 & 1501 & 1250 & 30 & 251 \\
\hline $\bar{t} \pm \alpha$ & $14.1 \pm 0.1$ & $11.2 \pm 0.4$ & $16.7 \pm 0.4$ & $33.8 \pm 0.6$ & $21.0 \pm 2.7$ & $31.3 \pm 1.2$ & $56.2 \pm 2.1$ & $46.4 \pm 12.3$ & $52.5 \pm 5.0$ \\
\hline $\mathrm{Mo}$ & 4 & 4 & 8 & 12 & 13 & 17 & 35 & 37 & 32 \\
\hline $\mathrm{Me}$ & 10 & 8 & 12 & 27 & 14 & 25 & 48 & 41 & 41 \\
\hline$\Delta t$ & $1-29$ & $1-23$ & $1-34$ & $1-66$ & $1-44$ & $1-62$ & $1-111$ & $1-81$ & $1-109$ \\
\hline
\end{tabular}

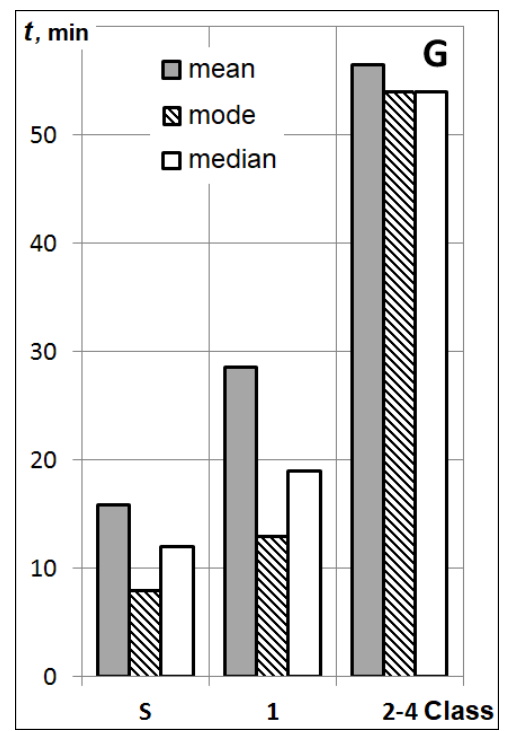

Figure 14. Statistical parameters of G-flares

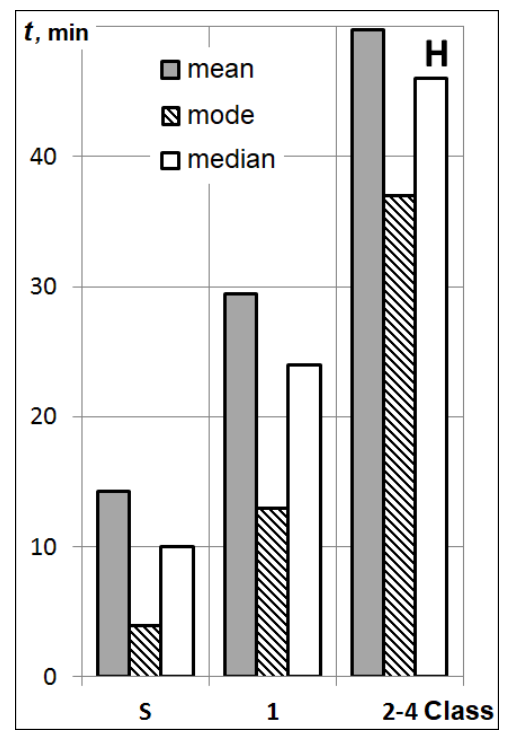

Figure 14. Statistical parameters of H-flares

In flares of all the types considered, the flare decay time increases with increasing flare class. At the same time, they differ significantly in duration of the main phase both from each other and from $\bar{t}$ for all flares (Table 11, Figure 16).

Regardless of the flare class, flares with one brilliant point have the shortest main phase; flares with several intensity maxima and two-ribbon flares, the longest one. With an increase in flare class (except for D, K, and U flares) they change their relative position (Figure 16).
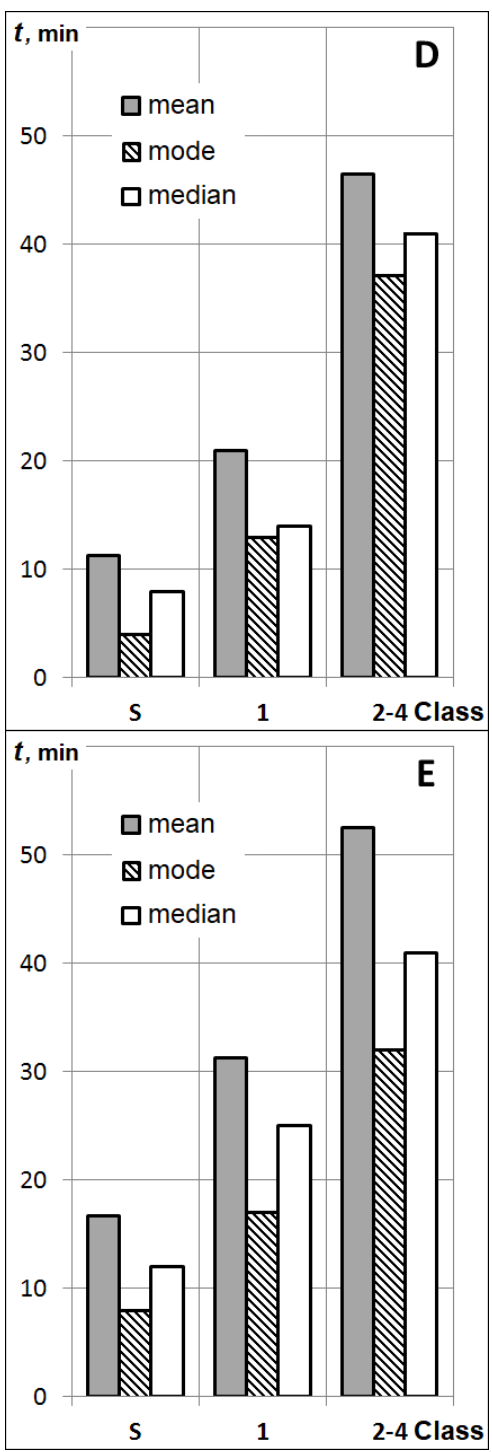

Figure 15. Statistical parameters of D- and E-flares

For example, flares of explosive type (V) are reclassified as having longer duration of the main phase. Eflares, on the contrary, fall into the category with shorter main phase.

In features of development, explosive and tworibbon flares are noticeable [Borovik, Zhdanov, 2018]. High percent of V-flares occur in regions of filament decay (S). These flares most often have one brilliant point (D). In the structure of virtually all two-ribbon flares there are several centers of increased brightness (E).

A considerable part of two-ribbon flares feature several intensity maxima (K). Among them is the highest 


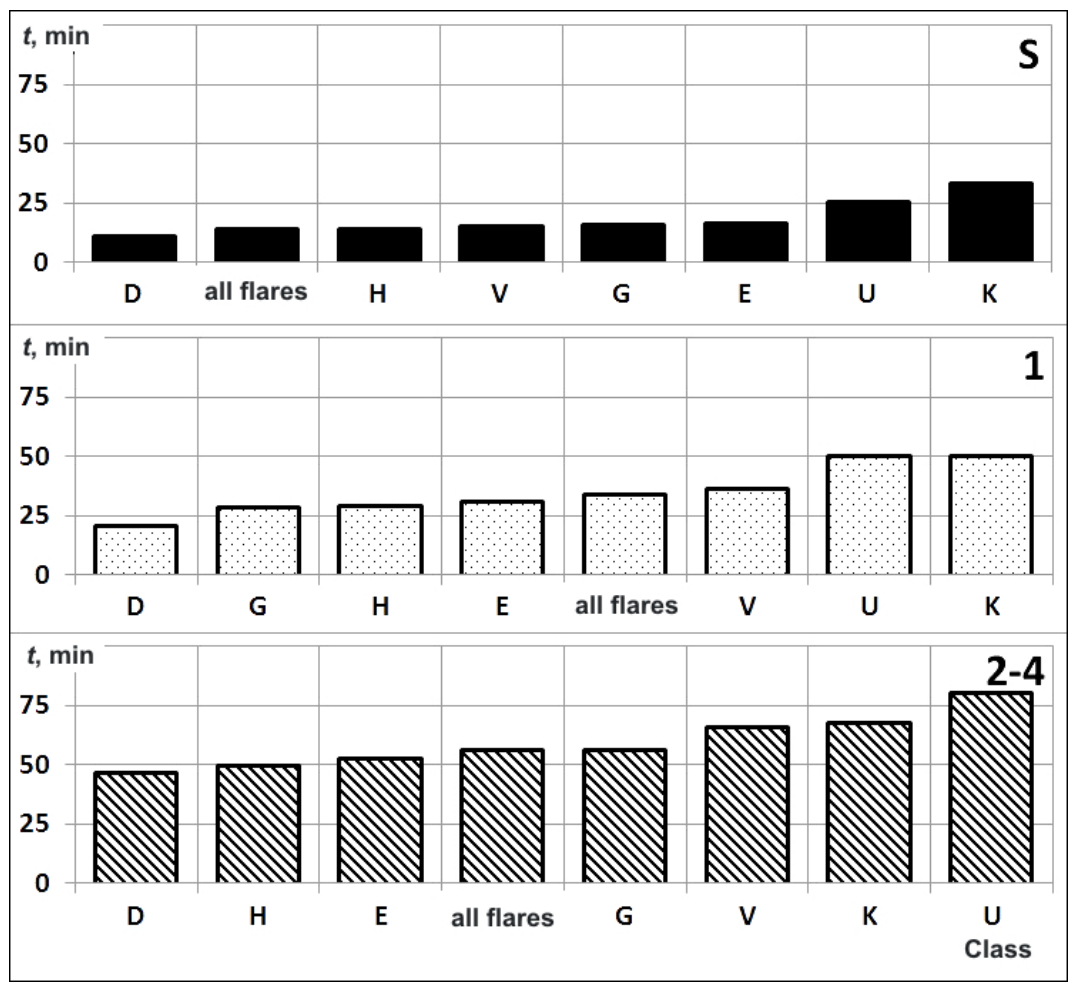

Figure 16. Mean flare decay time for flares of individual types versus flare class. The histograms are plotted in ascending order $\bar{t}$

\begin{tabular}{|l|c|c|c|c|c|c|c|c|}
\hline Class & $\mathrm{D}$ & $\begin{array}{c}\text { all } \\
\text { flares }\end{array}$ & $\mathrm{H}$ & $\mathrm{V}$ & $\mathrm{G}$ & $\mathrm{E}$ & $\mathrm{U}$ & $\mathrm{K}$ \\
\hline $\mathrm{S}$ & 11.2 & 14.1 & 14.3 & 15.4 & 15.9 & 16.7 & 25.4 & 33.5 \\
\hline 1 & 21.0 & 33.8 & 29.5 & 36.6 & 28.6 & 31.3 & 50.0 & 50.6 \\
\hline $2-4$ & 46.4 & 56.2 & 49.8 & 66.3 & 56.5 & 52.5 & 80.2 & 67.6 \\
\hline$\Sigma$ & 12.1 & 16.2 & 18.1 & 18.0 & 17.9 & 20.2 & 43.8 & 39.4 \\
\hline
\end{tabular}

Table 11

Table 12

\begin{tabular}{|l|c|c|r|c|c|c|}
\hline Class & $N$ & $(N, \%)$ & $\bar{t} \pm \alpha$ & $\mathrm{Me}$ & $\Delta t$ & $L$ \\
\hline $\mathrm{S}$ & 1570 & 46.3 & $84.3 \pm 1.6$ & 74 & $60-119$ & $60-531$ \\
\hline 1 & 1189 & 35.0 & $91.4 \pm 2.4$ & 78 & $60-132$ & $60-693$ \\
\hline $2-4$ & 634 & 18.7 & $108.9 \pm 4.4$ & 90 & $60-178$ & $60-498$ \\
\hline$\Sigma$ & 3393 & 100 & $91.4 \pm 1.4$ & 78 & $60-136$ & $60-693$ \\
\hline
\end{tabular}

percent of flares covering umbrae of large sunspots $(Z)$.

From the results it follows that the generalized statistical parameters of solar flares are made up of the parameters of individual types of flares. We can assume that they can vary depending on a solar cycle phase.

\section{ULTRA-LONG MAIN PHASES OF SOLAR FLARES}

The main phase of solar flares usually lasts for one hour. However, there are cases when it lasts much longer (more than $60 \mathrm{~min}$ ). Information on solar flares with ultra-long main phases, including the range of flare decay time $L$, is given in Table 12 . Over the period of interest, there occurred 3393 such flares, which is $2.9 \%$ of their total number.

Flares of all classes can have an ultra-long flare decay time. The maximum flare decay time for class $\mathrm{S}$ and 1 flares are 531 and $693 \mathrm{~min}$; for large flares, $498 \mathrm{~min}$.
For $90 \%$ of such solar flares, the main phase lasts within 2-3 hrs. In very rare cases, it can last for about 12 hrs.

\section{CONCLUSIONS}

The results of the statistical analysis allow the following conclusions to be drawn:

1. Using an extensive statistical material, we have determined the mean duration of the main phase for class S, 1 and 2-4 flares.

We have confirmed the tendency for an increase in the mean duration of the main phase with an increase in classes of flare area and brightness [Smith, Smith, 1966; Temmer et al., 2001].

2. It has been shown that, despite the well-defined tendency, distributions of flare decay time for flares of all classes overlap significantly. There is no direct functional relationship between flare decay time and flare area. 
3. It has been established that flare decay time depends on a type of flare. Flares with one brilliant point have the shortest mean duration of the main phase; flares with several intensity maxima and two-ribbon flares, the largest one.

4. We have identified 3393 flares with the main phase duration of more than 60 min. In $90 \%$ of these solar flares, the duration of the main phase is $2-3 \mathrm{hrs}$. However, in some cases, the main phase can last for about 12 hrs.

\section{REFERENCES}

Abramenko S.I., Dubov E.E. Ogir M.B., Steshenko N.E., Shaposhnikov E.F., Tsap T.T. Photometry of solar flares. Izvestiya Krymskoi astrofizicheskoi observatorii [Bull. of the Crimean Astrophysical Observatory]. 1960, vol. 23, pp. 341361. (In Russian).

Altas L. Spotless flare activity. Solar Phys. 1994, vol. 151, no. 1, pp. 169-176.

Altyntsev A.T., Banin V.G., Kuklin G.V., Tomozov V.M. Solnechnye vspyshki [Solar flares]. Moscow, Nauka Publ., 1982, 246 p. (In Russian).

Barlas O., Altas L. The duration of spotless flares. Astrophys. Space Sci. 1992, vol. 197, no 2, pp. 337-341.

Borovik A.V., Myachin. D.Yu. The spotless flare of March 16, 1981. I. Preflare activations of the fine structure of the chromospheric fine structure. Solar Phys. 2002, vol. 205, no. 1, pp. 105-116.

Borovik A. V., Myachin D.Yu. Structure and development of the spotless flare on March 16, 1981. Geomagnetism and Aeronomy. 2010, vol. 50, no. 8, pp. 937-949.

Borovik A.V., Zhdanov A.A. Statistical studies of lowpower solar flares. Distributions of flares by area, brightness, and classes. Solnechno-zemnaya fizika [Solar-Terr. Phys.] 2017, vol. 3, no. 1, pp. 34-45. (In Russian).

Borovik A.V., Zhdanov A.A. Statistical studies of lowpower solar flares. Distributions of flares by time of rise to the maximum brightness. Geomagnetizm i aeronomiya [Geomagnetism and Aeronomy]. 2018. (In print). (In Russian).

Borovik A.V., Myachin D.Yu., Uralov A.M. The model of extra-sunspot flare. Izvestiya Krymskoi astrofizicheskoi observatorii [Bull. of the Crimean Astrophysical Observatory]. 2016, vol. 112, no. 1, pp. 38-46. (In Russian).

Chistyakov V.F. Flares out of sunspots. Issledovaniya po geomagnetizmu, aeronomii i fizike Solntsa [Research on Geomagnetism, Aeronomy and Solar Physics].1988, iss. 79, pp. 70-75. (In Russian).
Dodson H.W., Hedeman E. Ruth. Major Ha flares in ce ters of activity with very small or no spots. Solar Phys. 19; vol. 13, pp. 401-419.

Giersch O. GONG Intersite H $\alpha$ flare comparison. J. Phys.: Conf. Ser. 2013, vol. 440, 0120062013.

Kopetskaya F., Kopetsky M. Characteristics of large chromospheric flares from Frittseva, Kopetsky, Švestka Catalogue. Issledovaniya po geomagnetizmu, aeronomii i fizike Solntsa [Research on Geomagnetism, Aeronomy and Solar Physics]. 1971, iss. 2, pp. 117-130. (In Russian).

Luo B. The flares of spotless regions. Proc. Kunming Workshop "Solar Physics and Interplanetary Travelling Phenomena”. November 21-25, 1983, Kunming, China. Beijing Science Press, 1985, vol. 1, p. 718.

Potzi W., Veronig A.M., Riegler G., Amerstorfer U., Pock T., Temmer M., Polanec W., Baumgartner D.J. Real-time flare detection in ground-based $\mathrm{H} \alpha$ imaging at Kanzelhöhe Observatory. Solar Phys. 2014, vol. 290, no. 3, pp. 951-977.

Priest E. Solar Magnetohydrodynamics. Moscow, Mir Publ., 1985, 592 p. (In Russian).

Rossada V.M. Statistical analysis of 6600 flares over 1965-1966. Vestnik Kievskogo Natsionalnogo Universiteta. Ser. Astronomiya [Bull. of Taras Shevchenko National University of Kyiv. Ser. Astronomy]. 1977, no. 19, pp. 49-55. (In Russian).

Smith H.J., Smith E. Solar flares. Moscow, Mir Publ., 1966, 426 p. (In Russian).

Solar-Geophysical Data. 1983, Part 1, January, no. 461, p. 30.

Švestka Z. Solar Flares. D. Reidel Publ. Co., 1976, 415 p. (Geophys. Astrophys. Monographs, vol. 8).

Temmer M., Veronig A., Hanslmeier A., Otruba W., Messerotti M. Statistical analysis of solar H $\alpha$ flares. Astron. Astrophys. 2001, vol. 375, pp. 1049-1061.

Ward F., Cornevall R.F., Hendle R. Solar flare observations from a pair of matched instruments. Solar Phys. 1973, vol. 31, p. 131.

Warwik C.S. Solar flare frequency and observing-time patterns. Astroph. J. 1965, vol. 142, no. 2, pp. 767-771.

Yatini C.Y. Characteristics of $\mathrm{H} \alpha$ flare in the solar spotless area. Majalah LAPAN. 2001, vol. 3, p. 53.

How to cite this article

Borovik A.V., Zhdanov A.A. Statistical research into low-power solar flares. Main phase duration. Solar-Terrestrial Physics. 2017. Vol. 3. No. 4. P. 5-16. DOI: $10.12737 /$ stp-34201701 